\title{
Bringing Technology to Students' Proximity: A Sociocultural Account of Technology-Based Learning Projects
}

\author{
Evode Mukama* \\ University of Rwanda \\ College of Education \\ PO Box 5039 Kigali, Rwanda \\ E-mail: emukama@ur.ac.rw; emukama01@gmail.com \\ * Corresponding author
}

\begin{abstract}
This paper depicts a study carried out in Rwanda concerning university students who participated in a contest to produce short documentary films. The purpose of this research is to conceptualize these kinds of technology-based learning projects (TBLPs) through a sociocultural perspective. The methodology included focus-group discussions and field notes to collect empirical data. The findings reveal that the more educational technologies capture objects of learning positioned in the students' sociocultural proximity, the more focused the learners' attention is on these objects. The study shows also that a change in learning projects may depend to a large extent on whether the technology relates to the students' sociocultural proximity, that is, taking into consideration students' physical, cultural, and contextual real world. The study recommends a community of learning/inquiry embedded in a collaborative, problem-solving dynamic involving cognitive support from peers, teachers, external specialists, and the wider community.
\end{abstract}

Keywords: Community of learning/inquiry, technology-based learning project, sociocultural proximity, Rwanda, ICT in education, knowledge construction

\section{Bibliographical notes:}

Dr Evode Mukama is a senior lecturer at the University of Rwanda, College of Education. His research interests include knowledge building in computersupported social practice, ICT-based learning projects, and youth employabilityenhancing skills through job training centres. 


\section{Introduction ${ }^{1}$}

Rwanda's Vision 2020 aims to transform the country into a knowledge-based, technology-led, and middle-income society by the year 2020. Here, Information and Communication Technology (ICT) is considered as a ubiquitous tool that will energize the country's socio-economic development. To achieve this vision, the education sector strategized skills development through six main projects (Government of Rwanda, 2011):

- ICT Professional Certification Programmes: Developing a competent and relevant ICT professional base.

- SchoolNet: Increasing the penetration and usage of ICT in 9 and 12-year basic education.

- ICT training for teachers: Developing teacher capabilities in and through ICT.

- Rwanda Education and Research Network (RwEdNet): Enhancing teaching, learning and research through ICT in Higher Education.

- Open, Distance and e-Learning (ODeL): Increasing access to education.

- Digital Library: Increasing access to scientific publications for educational institutions and the general public.

The implementation of such projects requires a rigorous body of research and evidence to inform and guide the practice. Some studies conducted in a Rwandan context have already shown that the effective use of ICT in schools as a tool for enhancing learning depends to a great extent on change of attitude toward the accountability, ownership and commitment of different stakeholders in education (Mukama and Andersson, 2008).

Previous research has tried to understand how new knowledge can be constructed through technology-supported collaborative learning (Mukama, 2008; 2009; 2010). For example, Mukama (2009) demonstrated that access to ICT with adequate training alone does not necessarily prompt education beneficiaries to use this tool for improving their everyday learning activities. Arguably, Rwanda can count on active ICT users, known as change agents, who could provide cognitive support to the community, especially teachers and students, to implement the ICT skills-development projects mentioned above. Accordingly, understanding the process of knowledge construction in ICT-enhanced learning practice can be best achieved through an investigation of students' and teachers' interaction and action.

The focus of this study is on ways of organizing students' learning projects within a technology-based sociocultural practice. This study is the first phase of a broader post-doc project on teacher professional development using project-based learning in technology-rich environments. The second phase will explore how teachers can cope with such settings to improve the quality of teaching and learning.

1 I wish to express my gratitude to Gunilla Jedeskog for her support in the conceptualisation of this paper. My thanks go also to the sponsor of my post-doc programme, the co-operation project between the National University of Rwanda and the Swedish International Development Agency, Sida Ref. 2004-000746. 


\section{Theoretical Framework}

\subsection{Project-Based Learning}

UNESCO (2011) identified the project-based learning approach as one of the strategies that could be used to boost ICT teacher professional development. Morgan (1983) explains that project-based learning reflects an approach of organizing learning activities around authentic and real-world themes or issues in such a way that students are given some degree of responsibility and autonomy to make their personal investigation in order to develop an understanding that they will share with the classroom.

Dewey $(1916 ; 1938)$ states that students learn better from worthwhile experiences. Consequently, learning should not be understood as a process of absorbing knowledge through a transmission mode of teaching; it is rather construed through actions and through experiencing the consequences of our actions. Thus, projectbased learning is rooted in Dewey's educational philosophy according to which project work implies that the students should take more responsibility in learning and that the object of learning should be relevant to the students' intrinsic needs.

According to Graaff and Kolmos (2007), the renaissance of project-based learning in social sciences emerged in the aftermath of student revolts in the late 1960s as an educational approach that could generate change in society. This new interest in project work materialized in Northern Europe. This approach emphasized professional discipline boundary crossing, students' autonomy to control their learning progress, teamwork, and integration of theory and practice.

\subsection{Learning Projects and Technology-Rich Environments}

Project-based learning in technology-rich environments has been supported by Schneiderman (1998) in his article called Relate-Create-Donate: a teaching/ learning philosophy for the cyber-generation. Though developed as a result of personal experiences and observations of students learning activities and not systematically based on empirical research, Schneiderman (1998, p. 25) has the merit to emphasize 'collaborative group experiences based on ambitious, authentic, service-oriented projects' in technology-rich learning environments. The process of learning with projects is described by Scheiderman in three phases:

- The Relate component involves team efforts to clarify, define a project to explore, and plan how to handle it.

- The Create component implies that students try to search appropriate solutions and investigate ways to develop meaningful projects individually or collectively.

- The Donate component means that student products have to be shared with external customers, the public or the community.

Morgan (1983) and Scheiderman (1998) point out that focus in their approaches to learning is all about the process and the products. This statement resonates with Mukama and Andersson's (2008) findings that coping with change in ICT-based learning environments requires learning conditions that can enable students not only to create new things and to solve problems that they encounter in their everyday lives, but also to demonstrate the achievements of their creativity and problem-solving abilities. Furthermore, previous findings on computer-supported 
collaborative learning (Mukama, 2010) indicate that it is not enough to put students together and pretend that they will work hand in hand to create a new and common understanding satisfactory to the team members. Mercer (1995) encourages working in small groups, using exploratory talk as a powerful discourse that can support the students as they construct a joint meaning. This discourse involves a critical analysis of individual thoughts, allowing time to explain and evaluate individual propositions, providing explanation, elaborating on and/or contrasting others' arguments when necessary, creating a progressive discourse, and aiming to reach joint achievements.

The use of project work to enhance learning has attracted a number of researchers. For example, ChanLin (2009) demonstrates that project-based learning can increase students' abilities to synthesize and elaborate on content and can also boost their skills to handle scientific exploratory activities. ChanLin underpins that the teacher's coaching role in this approach is key to students' success. Danford (2006) reports that project-based learning may help students acquire skills needed in the workplace and may allow companies to afford cost-effective resources (students) and expertise (faculty staff). Though project-based learning is commonly used, Hanney and Savin-Baden (2013) assert that it seems to be rarely theorized. Therefore, they explain that this results in a failure to provide credible accounts of a unified framework. The present study is a tentative contribution to fill this gap in the study of technology-rich environments.

\subsection{A Reflective Dimension in Negotiating Meaning}

The concept of 'reflective practitioner' is often linked to teachers' professional practice, with occasional reference to Dewey (1933) and Schön (1983). The central tenet in the educational philosophy of these two authors is the dynamic relationship between preconception such as theories and action. Dewey (1933) explains that action is enlightened by the reality on the ground. Schön (1983) proposes an epistemology of practice based on reflective inquiry. Because learning environments are dynamic, complex, and unpredictable, preconceived ideas, theories, and knowledge may not fit the uniqueness and uncertainty of different situations of inquiry. Thus, to cope with these situations, Schön suggests reflection-in-action and reflection-on-action.

Here we can establish a close connection between project-based learning and reflection-in-action and reflection-on-action: learning and action go hand in hand, theory and practice are interrelated; they inform and drive each other. Projectbased learning and reflection-in and -on-action are service-oriented and both students and the practitioners are continuously empowered while they learn in practice; in other words they develop new knowledge to handle later situations.

Kember et al. (2008) state that the objective of learning should be relevant enough to motivate university students in terms of integrating content to local cases, relating cultural resources to students' intrinsic needs, producing something useful, and addressing current issues. As pointed out by Marton and Säljö (1976), learning can be seen as a means of developing meaning, that is, understanding things in such a way that students can make sense of the world, and can create or invent new ways of seeing. The present study is embedded in this conception of learning. 


\subsection{Sociocultural Theory}

The term 'sociocultural' refers to a cognitive theory. Interdependency and coconstruction of human development processes are central to this perspective. According to Vygotsky (1978), the process of knowledge construction takes place through a discourse between people at the social level (interpsychological) and then at the individual level (intrapsychological). Thus, knowledge appropriation implies that individual learners participate actively in shared experience that "is oriented to action of personal and social significance and to the continual enriching of the framework within which future experience will be interpreted" (Wells, 1999, p. 85).

Vygotsky (1978) asserts that cognitive support from a teacher or another person more experienced can expand students' personal learning through the zone of proximal development (ZPD). The ZPD has been conceptualized in learning practices as a process of learners' guided participation (Rogoff, 1995) or guided knowledge building (Mercer, 1995), or as a process of scaffolding (Bruner, 1978) with a more skilled partner. Stetsenko (1999) explains that the problem of analysing learning practice in the ZPD is that emphasis is often placed on interaction between teachers and learners and that the content receives little attention. This is one of the issues the current study tries to address.

Thus, the sociocultural theory appears to be comprehensive to help explore interrelatedness of social and technological artefacts (Bliss and Säljö, 1999) through project-based learning. To capture the human technological dynamic in project-based learning, a 'technology-based learning project' (TBLP) is proposed as an approach aiming to engage students in learning and knowledge development. The next section will bring more light to the sociocultural theory as it is used in this study.

\subsection{Situated Learning in Technology-Based Environments}

Bliss and Säljö (1999) state that humans, technologies, and contexts shape learning in a particular way. Thus, the context can reflect how humans cope with new technologies. The present research study borrows the concept of 'proximity' emanating from Gestalt psychology and often used in media studies. Huxford (2007, p. 670) explains that proximity "refers to the distance between events and the news audience, with a rule-of-thumb that an event occurring close to audience members is more newsworthy than a similar occurrence farther away.” This means that the context is interpreted in terms of mental associations based on proximity or closeness. For example, in a study of students' interaction with web-based literature in a Rwandan multilingual context (Mukama, 2008), it was revealed that student thoughts in computer-supported social practice were better structured and organized in their mother language, Kinyarwanda, with which they were more conversant than the official languages of instruction, which were at the time English and French. Students' preferences to analyse English and French webbased literature using Kinyarwanda can be interpreted in terms of discourse proximity.

In fact, there are different types of proximity, and these can result in different learning strategies. For example, Gahamanyi's (2010) study of mathematical organizations within a Rwandan context demonstrates that student teachers tend to shift their focus from using pseudo-problems for just increasing knowledge, toward more culturally contextualized problems for supporting the production of a 
meaningful product when the use of mathematics is brought to the students' real life workplace proximity. In a study on computer-mediated activities in children's everyday lives, Aarsand (2007) argues that the dichotomization between master and apprentice, public and private, real and virtual, and subject and object can be interpreted in terms of the closeness between the students and their everyday experiences with technology. Thus, proximity seems to be meaningful in shaping student learning.

Rogoff (1995) argues that by being actively involved in a community, students interact and collaborate with others who are more experienced (apprenticeship) and through guided participation they construct new knowledge and skills that they can use to handle later situations (participatory appropriation). In a different paper, Rogoff et al. (1996) refer to this developmental process as a community of learners aiming to advance learning in sociocultural practice. For example, Northedge (2002) asserts that students benefiting from guided participation from specialists in a discourse community not only create authentic meanings framed in the specialists' discourse, but they also develop a new identity as members of legitimate speakers within this community. In this connection, Engeström (1999) identifies lateral transitions between communities of practice as sideways movement or boundary crossing between, for example, learning institutions and the workplace and between students and the community. According to Lave and Wenger (1991, p. 14), meaning, understanding, and learning are situated in "social situations in which they occur." Situated learning entails that students participating in a community change during the learning process. Individual transformation takes place through negotiation of responsibilities, redefinition of membership, and engagement in the sociocultural practices of a community.

There is a clear resonance between the community of learners and Garrison's (2011) notion of community of inquiry. The central tenet of the community of inquiry is a collaborative constructivist approach of learning activities. Garrison underpins that learning implies, first, social presence, that is, interaction and interpersonal relationships in the community. Second it implies cognitive presence, indicating how a joint understanding evolves in the resolution of a problem or a dilemma. Finally, it requires a teaching presence reflecting leadership of more experienced others. In this connection, Wells (2002) argues that teachers must be inquirers themselves if their students have to be co-inquirers.

\subsection{Research Questions}

As mentioned above, sociocultural contexts uniquely shape learning with technology-based-learning experiences. Thus, taking into consideration the need to develop a unified construct of project-based learning in technology-rich environments, the present study aims to conceptualize technology-based learning projects (TBLPs) within a sociocultural perspective and addresses the following research questions:

- What conditions drive students to focus on an object of learning in TBLPs?

- How does reflection support the students' experience in TBLPs?

- How is new meaning constructed in the students' efforts to produce a documentary film? 


\section{Method}

\subsection{Participants and Settings}

Data was collected in 2010 in Rwanda during a competition for a short documentary film under the theme 'A day of the student at the university'. Three optional sub-themes were proposed to the contestants: teaching and learning experience; service to the community; and cultural and extracurricular programmes. The documentary contest, the first of its kind at that university, aimed to encourage teachers and students to engage with audio visual multimedia-based education, as a way of improving teaching and learning methods. The exercise lasted for a period of two months.

For candidates to take part in the competition they had to be registered as university students. They were requested to form teams of a minimum of three and a maximum of four members. Six teams of four participants each and five teams of three participants each were created. The departments were represented as illustrated in Table 1.

Table 1: Departments’ Representation

\begin{tabular}{lccc}
\hline Department & Men & Women & Total \\
\hline Media Studies & 10 & 4 & 14 \\
Biology & 0 & 3 & 3 \\
Business Administration Sciences & 1 & 0 & 1 \\
English & 2 & 2 & 4 \\
Applied Statistics & 2 & 2 & 4 \\
Civil Engineering & 3 & 1 & 4 \\
Management & 1 & 1 & 2 \\
Electricity and Electronics & 1 & 0 & 1 \\
Computer Science & 4 & 2 & 6 \\
\hline Total & 24 & 15 & 39 \\
\hline
\end{tabular}

The 39 participants in this competition (24 men and 15 women) voluntarily agreed to take part in this study. All participants were undergraduate students: first year (1), second year (19), third year (12), and fourth year (7). After receiving a formal approval to participate in the competition, they received a two-day training session on script writing, video shooting, and some video camera techniques. They were also briefed on group work strategies. This tutorial was conducted by a professional experienced in documentary films and included various illustrative documentaries. Technical support was also provided whenever required by the contestants throughout the assignment. From the beginning, the final productevaluation criteria were explained to the contestants. These evaluation criteria were based on four critical factors, namely the relevancy of the topic, the content, the production skills, and the education value. Only the students from the Department of Media Studies, representing 38\% of the contestants, had studied a credit course on video production. The contestants from Media Studies were represented in 6 out of the 11 teams. Most other contestants were lay people in video production, however, a few of them had previously acquired some skills on their own. At the 
closing stage of the assignment, each team had managed to produce a short documentary film that was 12 to 15 minutes long.

\subsection{Procedures}

Focus group discussions were the main instruments used to collect data. These discussions were organized during the public screening week of the short documentary films, held before the final evaluation conducted by a jury committee of experts. From the outset of the competition, research assistants were hired and trained to follow-up on the individual teams as participant observers, making field notes and writing analytical memos. Each team of contestants formed a focus group, and the duration of each discussion was approximately 15 to 20 minutes. Topics of the focus-group discussions emerged from field notes. The discussions were conducted in Kinyarwanda, audio-recorded, and transcribed verbatim. Both the focus-group transcripts and the field notes were later translated into English. In order to ensure confidentiality, the participants were given fictional names used in this paper.

Data analysis was principally inspired by a qualitative approach. The research assistants, supported by the researcher, started individually coding salient issues emerging from the transcripts and field notes. They wrote analytical memos that helped to identify relationships between emerging concepts. These memos were then jointly compared and similar analytical ideas were set up under themes which were then grouped under categories. The latter became the headings of the next section on findings. Each category was backed by supporting quotations from the focus-group transcripts, and these were explored accordingly. The theoretical framework was developed in conjunction with the analytical process. The data analysis influenced the selection of the theoretical perspective which was gradually changed and adapted during the interpretation process.

\section{$4 \quad$ Findings}

\subsection{Technologies vis-à-vis Students' Sociocultural Proximity}

What learning conditions drive students to focus on an object of learning in TBLPs? The object of learning in this study refers to the documentary films that students were trying to produce and the content that they conveyed. The findings show that students' focus on objects of learning depended to a large extent on the relationship between the learning projects and the students' sociocultural proximity. The more the technologies portrayed an object located close to their everyday lives, the more focused was the students' attention. Yohani, one of the contestants, who was a student in Media Studies, provided an example of this phenomenon:

The documentaries summarized university students' everyday lives, hence their interest in watching them. Some students saw their pictures in the restaurant while eating. Others saw themselves working around and so on. They find this interesting because it is about their own lives. In other words, our own lives attract much more our attention and we like it... That is how people are made.

In fact, the university community expressed some enthusiasm for watching their own stories, the context they live in, their own challenges and the cast or actors who were mainly students and staff. 
The organizing committee played a facilitation role in scaffolding students' proximity, supporting the contestants to focus their topics on their real-life experiences. The committee proposed the main theme of the contest and the three optional sub-themes (see the section on method). Following a request from the committee, the groups of contestants each submitted a one-page narrative summary about a project of their choice. At the beginning, most of the proposed projects were very broad. Through discussion with the organizing committee, the contestants managed to narrow down the projects. Six teams focused their short documentary films on individual characters (famous university students) depending on their outstanding abilities. Three groups developed their projects on student learning experiences. One group studied the university career advisory centre and the last group reported issues regarding environmental protection at the university. Once the project narrative summary was agreed upon, each group developed a script. Planning, script writing and related tutorials took considerable time before the groups could start collecting information, which was mainly through shooting, interviews, and literature. Both the project narrative summary and the script were often revised, elaborated on, or further explained due to the feedback from the organizing committee or as new experiences were acquired.

Learning projects were organized in such a way that workplace real-life experiences were brought to the students' proximity. Monika, a fourth-year contestant from Applied Statistics, explained her new experience with enthusiasm:

It is about the experience of life, experience to work together in a group; experience to work under stress; experience of doing a lot of things in a short time; commitment and determination; having time and plan for our activities; experience of my personal everyday life. It is also a kind of discovery. We are discovering the university way of life.

Another aspect of proximity observed during the development of the documentary films and expressed in the contestants' discussions was about the discourse; that is, the language in use. The language through which the contestants' stories were narrated was selected intentionally depending on how conversant the target audience was with it. For example, a woman contestant from the Department of Biology, Alisa, formulated the choice of the language in these words:

We used Kinyarwanda because it is the language spoken by many people and is user friendly to most Rwandans.

Observations revealed that the groups' working language was predominantly Kinyarwanda, the contestants' mother tongue, with some mixing of English and French. On other occasions, external factors influenced the choice of the language to use. For example, a group of three contestants planned an interview in English with one of the staff members. After the planning, they went on to hand over the questions on a piece of paper to that staff so that she could prepare answers beforehand. She objected to being interviewed in English, arguing that she was more conversant with Kinyarwanda. This caused the group to translate the questions into Kinyarwanda and the interview then began. Similar experiences occurred in most groups of contestants as interviewees preferred to speak in a language that they understood better. This reveals that proximity is not confined to the visual perception between external items close together but also to the mental 
association between cultural tools, such as the language of communication and objects of a conversation, and between learning projects and real life experiences.

\subsection{Developing TBLPs through Reflection}

This section explores the contestants' practice in a spiral pattern of past, current and future experiences regarding the learning projects. In fact, learning projects (producing documentary films) stimulated the contestants and even other students to reflect on their own everyday practice. The technology used, especially video cameras, computers and audio recorders, offered a unique and advantageous opportunity to replay the footage and/or audio recordings. Thus, technology mediated reflection-in and -on-action between team members. They often exchanged qualitative feedback regarding the content of their projects and their performance.

At least once a day, each group of contestants met a member of the organizing committee to assess the progress. Group members briefed the committee member on information gathered and what they planned for the next day. A committee member could eventually ask any question regarding evidence collected, the process, and any prediction regarding the way forward. On different occasions, group members either adjusted or edited their work. These 10- to 15-minute planning and recap sessions with committee members took place primarily during the first few days of the contest. Gradually, the groups organized the sessions on their own without the presence of a member of the committee. However, the latter could attend such sessions occasionally or on request from any group. For example, in one of the groups, a young man convinced to be more experienced in video production was trying to work in isolation from other group members. The organizing committee intervened and reminded them about group work strategies. Because that behaviour was recurrent, a member of the committee took the initiative to participate in that group's activities on several occasions. This encouraged its members to collaborate again and pursue a common goal.

Public screening presented another strong opportunity for reflection on the learning projects. After the screening of the first three documentaries, Bonane from the Department of Electricity and Electronics highlighted the lessons learned:

From these films, I learned that we are able to do many interesting things. I couldn't imagine that some of our colleagues were able to produce such good films. These films helped me to reflect on myself. I evaluated myself: self-evaluation from problems faced by students.

The contestants' critical reflections were principally drawn from their previous experience in their respective faculties, as it can be analysed from Luwiza's arguments:

In the Department of Media Studies we learned different things such as long shot, medium shot and so on. It was projected on a screen. We used to memorize these things without any idea of how we should put them in practice. However in our team, it was very nice. We took our time to shoot and use different techniques; it was wonderful to realize that we were linking this [practice] and what we learned.

Luwiza, a female contestant from Media Studies, clearly differentiated her experience of learning what was projected on the screen in her department with learning 
imbedded in practice. Most of the time, reflection on the contestants' practice demarcated past and present experiences as well as their future expectations. Polina, a woman contestant and a student from the Department of Applied Statistics expressed her reflection through a trajectory of activities:

Some people used to believe that good products were those made from Europe or America. We have seen the products made by our fellow students like us. I believe that we, us as Africans, are able to design, shoot and make films similar to those produced in Europe and America. We should not underestimate our potential.

In this excerpt, Polina's conclusion was future-oriented, emerging from contrasting her past and current experiences. Her conclusion positioned a new learning dynamism against traditional practice. The importance of reflection in a TBLP can be revealed through the decisions made by some contestants. Half of them reported that they would like to invest in doing business in video production. A quarter of them claimed that they had decided to conduct a video production study in partial fulfilment of the requirements for their bachelor's degree programmes. The contestants considered change as part of their own responsibilities and as a way to prepare for their future (participatory appropriation), that is their professions through an interplay of the past (what people used to believe), current practice (outcomes of their learning projects), and the future (students' potential to undertake other related initiatives).

\subsection{Outsiders' Perspectives on Students' Learning Projects}

The contestants' enthusiasm stemmed from both individual group achievements and from the public satisfaction vis-à-vis the products. Emanweli, from the Department of English, explained the benefits of sharing their documentary films with the university community in the following terms:

I felt extremely happy to see such many people coming to the auditorium to watch our product. This brought me to think in a different way. It showed me that this was just the beginning. After I heard from the people appreciating the documentaries we were screening in the auditorium, I was encouraged to go forward and achieve something greater in my life.

Feedback came also from some specialists who helped contestants to improve their learning projects. Nine out of eleven groups received assistance from more experienced people from inside and/or outside the campus, especially in shooting and editing. For example, a jury committee composed of seven specialists (four in media, journalism, and communication; one in quality assurance, and two in drama and modern languages) provided written recommendations to contestants to help them improve their learning projects. The groups used these kinds of annotations to review and improve their work.

Some contestants experienced a potential partnership between external specialists and students. Alisa from the Department of Biology and whose learning project was focused on environment protection described her group experience in working with some university teachers as follows:

We discussed with a teacher, a specialist in environmental management and toxicology. She taught us how we could manage waste practically and scientifically. I realized that teachers do their work with students and they get good results. We are like their partners. 
Teachers provide advice and by so doing, they play an important role as we do when we collaborate with them. It was a partnership and a win-win situation.

This suggests that an external audience may play a prominent role in encouraging students to improve the quality of learning in technology-based projects and may help them think big. Furthermore, the findings show that external specialists can help the students to shift toward higher order thinking through guided participation.

\subsection{Constructing New Meaning in a TBLP}

How is new meaning constructed in the contestants' efforts to produce a documentary film? Drawing from the findings, the contestants tried to create strategies that could help them achieve joint meaning. Emanweli from the Department of English reported how he managed to team up with students from Media Studies:

As I thought I was not a professional [in documentary film], my upper most intention was to work, of course, with professional journalists [students in Media Studies]. I thought they were strong enough to play a very important role throughout the process. I thought my role was most importantly script writing.

The eleven groups were able to organize their work and share roles and responsibilities among their members. This research assessed individuals' strengths in completing the tasks of their assignments, taking into consideration how they shared responsibilities. Most contestants reported that throughout the implementation of the plans, individuals voluntarily undertook - based on their abilities - to coordinate specific tasks from the plans. Andereya from Civil Engineering asserted:

In our team work, we assessed where everyone could fit better. We shared responsibilities according to each one's talents, availability, and depending on each one's own views.

In addition to the active involvement of individual contestants, findings reveal that teammates worked collaboratively in order to reach their common objective and the deadline. Most contestants claimed that they acquired something new through collaboration. Mariko from Media Studies explained how his teammates provided cognitive assistance to their colleagues:

Usually in journalism nobody is weak, nor is anybody excellent. We all follow what we call 'editing'. This means that, for our group, when we did something, we had to request others' views. We discussed critically each other's ideas.

This utterance illustrates how a group helped its members to learn from each other through negotiation of new meaning in what Mariko called 'editing'. This may also show that apprenticeship is central in building knowledge in a TBLP approach.

The unique communication options offered by technology during the contest allowed groups the possibility to choose and use mediating tools according to individual needs. Some groups used phone calls and electronic mail to exchange ideas from a distance. The contestants used different types of cameras to capture video pictures. A number of different computer software packages, such as Adobe Premiere, Adobe Audition, and Movie Maker, were used to edit the contestants' films. Creativity in a multifaceted TBLP played a determining role in searching for solutions that matched team's specific problems or needs. 


\section{Conclusions and Discussion}

As mentioned above, the purpose of this study was to conceptualise students' learning projects in a technology-based sociocultural practice. To this end, the conditions driving students to focus on an object of learning in TBLPs were investigated. An examination of how new meaning can be generated through students' endeavours to produce a documentary film was conducted. Finally, an analysis of how reflection can support students' experience in such a technologyrich setting was performed. Thus, the findings of this study may be summarised in the following points:

- It seems that the more technologies capture objects of learning positioned in the students' sociocultural proximity (learning projects and the content they convey), the more focused learners' attention is on these objects.

- The teacher/facilitator can play a central role by scaffolding students' sociocultural proximity.

- TBLPs seem to imply a collaborative problem-solving dynamic involving cognitive support from peers, teachers, external specialists, and the wider community.

- Sharing students' service-oriented products with the community seems to motivate them to improve their TBLPs as they gain real-world experiences from the community.

- Encouraging students to work together in interdisciplinary project-based groups mediated by multifaceted TBLPs may lift them up to higher order thinking.

- Reflection on their experiences in a TBLP may support students to appropriate new meaning developed in their working groups.

The findings of this study revealed that students were enthusiastic about watching documentary films that were produced by their colleagues and that portrayed their own real-life experience. Learning in a TBLP was supported by discourse proximity: Students tended to use the language they were more conversant with, especially their mother tongue, in order to reach their audience. Thus, learning with technologies can become more effective when these pedagogical tools portray subjects and objects located in students' real-world proximity in terms of physical space, cultural tools and context. This implies that organising a technology-based learning environment would not be confined to the role of the teacher, but would also include that of technology designers. These findings are in accordance with Luckin (1999) who asserts that software design needs to capture the existing culture of the learning environment. The relationship between technologies and students' proximity may partly explain the reasons that some students and some teachers become passive or reluctant to use technology in teaching and learning. In fact, previous research findings (Mukama, 2009) have demonstrated that access to technology with adequate training alone does not necessarily prompt students or teachers to use this pedagogical tool. Nevertheless, some ICT in education policies and strategic plans take for granted integration of technology in education, pretending that this technology will automatically improve the quality of education. The contribution of the present study is to emphasize that change in learning practice may depend to a large extent on whether this pedagogical tool relates to 
the students' sociocultural proximity; that is, takes into consideration students' physical, cultural, and contextual real world.

This study demonstrates that though students have some degree of autonomy to conduct their learning projects, it appears clear that a teacher/facilitator plays a prominent role in scaffolding students' sociocultural proximity. The organizing committee proposed the theme and sub-themes of the projects in general terms. This committee invited the contestants to create project-based groups around topics of their choice. The committee members facilitated the groups to write both a narrative summary and a script for their projects. They also attended some group planning and recap sessions to stimulate reflection-in and -on-action. This assistance was purposely organized in order to support learning in the students' ZPD and to help them situate their projects in their real-life sociocultural proximity. This finding is also confirmed by ChanLin (2009).

A change in learning practice may also depend on whether students participate actively in a community of learning/inquiry. In fact, the findings disclose sideways transition between traditional classroom learning and selfdirected, real-world, and service-oriented projects. By focusing on informal, outof-classroom experience involving the production of a documentary film, we were surprised to note a blurring of hierarchy between students and external specialists, and between students and the community. Students were able to organize their own TBLPs, putting emphasis on learning objects located in their real-world proximity. The documentary films produced were not just simple projects emerging from the contest, but authentic and meaningful objects of learning for the students, the specialists, and the community. The findings indicate a potential partnership between students and external specialists in TBLPs. This partnership would mean that specialists involve students in their projects, which, in turn, would increase their productivity while students would gain new knowledge and cognitive support. Ferday (2006) points out that external specialists' advice can lift students to higherorder thinking while dealing with technology-led innovations. Thus, guided participation can support students to become legitimate speakers of the specialists' discourse (Rogoff, 1995; Northedge, 2002).

Given the interdisciplinary nature of TBLPs, the findings reveal boundary crossing between general academic programmes and profession oriented ones to mount a documentary film. For example, students from the Department of English or Statistics worked in unison with students from Media Studies or Computer Science, not as an addition of specific technical skills acquired from their disciplines, but as a community of inquiry aiming to extend each other's abilities through critical and creative thinking, and through problem-solving. In addition to these skills, the study shows that TBLPs may allow students to acquire interrelated skills and abilities from each other, such as communication technologies and their use vis-à-vis specific learning projects; interdisciplinary collaboration, even at a distance through technology; and higher-order thinking. Arguably, TBLPs can help to educate students as global citizens. Suarez-Orozco and Sattin (2007) recommend that education systems should aim to develop students as global citizens for the whole world, that is, people able to create social and cultural networks through the skills of critical thinking, communication, language, collaboration, and technology.

Lateral transition may generate innovative modes of collaboration for problem solving (Engeström, 1999). A practical contribution of this study, in addition to the empirical and theoretical dimension elaborated above, is that it appears that the implementation of technology-enhanced skills-development projects would require 
innovative solutions for their sustainability. This study suggests the need for a community of learning based on a collaborative problem-solving dynamic involving students' cognitive support from peers, teachers, external specialists, and the wider community. Accordingly, a community of learning would ensure that the participants have a common goal and strive to attain joint achievements through a constructive dialogue (Rogoff et al., 1996). Thus, this community of learning would entail that skills-development projects outsource from and feed each other through shared engagement. The interplay between apprenticeship, guided participation, and appropriation within a TBLP approach can explain to some extent why students who did not receive credit signed up and continued to be actively involved.

It seems that one of the key assets for teachers wishing to use TBLPs is to act as an agent to move to this approach as a community of inquiry. In this study, the role of the teacher is reflected in the activities conducted by the contest- organizing committee. The committee organized the tutorial support on script writing and other important techniques, such as group-work strategies, to enable the contestants to attend to their assignments. Additionally, the committee defined criteria and the process of evaluation. This requires planning skills on the part of the teachers. Moreover, learning by doing is central in TBLPs. Thus, teachers, in conjunction with their colleagues, could implement TBLPs and improve their practice through action and their own inquiries. Wells (2002) proposes that action research may be indicative in a community of inquiry. Hence, by sharing the results of their inquiries with other members of the community and by receiving feedback from external audiences, teachers may learn from best practices and cause other teachers to reflect on and/or adopt the approach. 


\section{References}

Aarsand, P. A. (2007). Around the screen. Computer activities in children's everyday lives. Linkoping University: LiU Tryck.

Bliss, J. \& Säljö, R. (1999). The human - technological dialectic. In J. Bliss, R. Säljö \& P. Light (Eds.). Learning sites: social and technological resources for learning (pp. 1-11). Oxford: Pergamon.

Bruner, J.S. (1978). The pragmatics of acquisition. In A. Sinclair, R. Jarvella \& W. Levelt (Eds.), The child's conception of language (pp. 39-55). New York: Springer.

ChanLin, L.-J. (2008). Technology integration applied to project-based learning in science. Innovations in Education and Teaching International, 45(1), 55-65.

Danford, L. G. (2006). Project-based Learning and International Business Education. Journal of Teaching in International Business, 18(1), 7-25.

Dewey, J. (1916). Democracy and education. An introduction to the philosophy of education (1966 edn.). New York: Free Press.

Dewey, J. (1933). How we think. A restatement of the relation of reflective thinking to the educative process (Revised edn.). Boston: D. C. Heath.

Dewey, J. (1938). Experience and education. New York: Collier Books.

Engeström, Y. (1999). Situated learning at the threshold of the new millennium. In J. Bliss, R. Säljö \& P. Light (Eds.), Learning sites: social and technological resources for learning (pp. 249-257). Oxford: Pergamon.

Ferday, E.R. (2006). Assessing technologies for teaching and learning: understanding the importance of technological pedagogical content knowledge. British Journal of Educational Technology, 37(5), 749-960.

Gahamanyi, M. (2010). Mathematics at work. A study of mathematical organisations in Rwandan workplaces and educational settings. Linkoping University: LiU Tryck.

Garrison, D. R. (2011). E-Learning in the 21st century: A framework for research and practice (2nd ed.). London: Routledge/Falmer.

Graaff, E. de \& Kolmos, A. (2007). History of problem-based learning and projectbased learning. In E. de Graaff \& A. Kolmos (Eds.), Management of change. 1-8. Rotterdam: Sense.

Government of Rwanda (2011). National ICT Strategy and plan NICI-2015. Kigali: Ministry of ICT in the Office of the President.

Hanney, R. \& Savin-Baden, M. (2013). The problem of projects: understanding the theoretical underpinnings of project-led PBL. London Review of Education, 11(1), 7-19.

Huxford, J. (2007). The proximity paradox. Journalism, 8(6), 657-674.

Kember, D., Ho, A. \& Hong, C. (2008). The importance of establishing relevance in motivating student learning. Active Learning in Higher Education, 9(3), 249-263.

Lave, J. \& Wenger, E. (1991). Situated learning. Legitimate peripheral participation. Cambridge: Cambridge University Press.

Luckin, R. (1999). Assessing children-computer collaboration in the zone of proximal development (the Vygotskian Inspired System (VIS)). In J. Bliss, R. Säljö \& P. Light (Eds.), Learning sites: social and technological resources for learning (pp. 194-209). Oxford: Pergamon.

Marton, F. \& Säljö, R. (1976). On qualitative differences in learning, outcome and process. British Journal of Educational Psychology, 46(1), 4-11. 
Mercer, N. (1995). The guided construction of knowledge. Talk amongst teachers and learners. Clevedon: Multilingual Matters.

Morgan, A. (1983). Theoretical aspects of project-based learning in higher education. British Journal of Educational Technology, 14(1), 66-78.

Mukama, E. (2008). Students' interaction with web-based literature: towards dissolution of language boundaries. International Journal of Knowledge and Learning, 4(5), 478-495.

Mukama, E. (2009). The interplay between learning and the use of ICT in Rwandan student teachers' everyday practice. Journal of Computer Assisted Learning, 25(6), 539-548.

Mukama, E. (2010). Strategizing computer-supported collaborative learning toward knowledge building. International Journal of Educational Research, 49(1), 1-9.

Mukama, E. \& Andersson, S. (2008). Coping with change in ICT-based learning environments: Rwandan newly qualified teachers' reflections. Journal of Computer Assisted Learning, 24(2), 156-166.

Northedge, A. (2002). Organizing excursions into specialist discourse communities: a sociocultural account of university teaching. In G. Wells \& G. Claxton (Eds.), Learning for life in the 21st century (pp. 252-264). Oxford: Blackwell Publishers.

Rogoff, B. (1994). Developing understanding of the idea of community of learners. Mind, Culture and Activity, 1(4), 209-299.

Rogoff, B. (1995). Observing sociocultural activity on three planes: participatory appropriation, guided participation, and apprenticeship. In J.V. Wertsch, P. Del Rio \& A. Alvarez (Eds.), Sociocultural studies of mind (pp. 139-164). Cambridge: Cambridge University Press.

Rogoff, B., Matusov, E. \& White, C. (1996). Models of teaching and learning: participation in a community of learners. In D.R. Olson and N. Torrance (Eds.), The handbook of education and human development: New models of learning, teaching and schooling (pp. 388-414). Oxford: Blackwell Publishers.

Suarez-Orezco, M. M. \& Sattin, C. (2007). Wanted: global citizens. Educational Leadership, April, 48-62.

Scheiderman, B. (1998). Relate-Create-Donate: a teaching/learning philosophy for the cyber-generation. Computers \& Education, 31(1), 25-39.

Schön, D. A. (1983). The reflective practitioner. How professionals think in action. London: Ashgate.

Stetsenko, P.A. (1999). Social interaction, cultural tools and the zone of proximal development: in search of a synthesis. In S. Chaiklin, M. Hedegaard \& U. J. Jansen (Eds), Activity theory and social practice (pp. 235-252). Aarhus: Aarhus University Press.

UNESCO (2011). UNESCO ICT competency framework for teachers. Version 2.0. Paris: UNESCO.

Vygotsky, L.S. (1978). Mind in society: the development of higher psychological processes. Cambridge, MA: Harvard University Press.

Wells, G. (1999). Dialogic inquiry: Towards a sociocultural practice and theory of education. Cambridge: Cambridge University Press.

Wells, G. (2002). Inquiry as an orientation for learning, teaching and teacher education. In G. Wells \& G. Claxton (Eds.), Learning for life in the 21st century. Oxford: Blackwell Publishers. 
